\title{
Effect of Elettaria cardamomum Essential Oil and Its Main Component (1, 8-cineole) on Brain Damage Caused by Cerebral Hypoperfusion by Suppressing Apoptosis and Inflammation in Rats
}

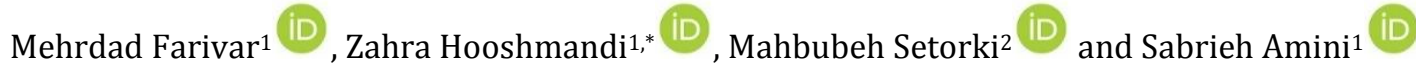 \\ ${ }^{1}$ Department of Biology, Sanandaj Branch, Islamic Azad University, Sanandaj, Iran \\ 2 Department of Biology, Izeh Branch, Islamic Azad University, Izeh, Iran \\ * Corresponding author: Zahra Hooshmandi, Department of Biology, Sanandaj Branch, Islamic Azad University, Sanandaj, Iran. Tel: \\ 09126342103; Email: zhoushmandi@yahoo.com
}

Received 2020 0ctober 15; Revised 2020 November 01; Accepted 2020 November 04.

\begin{abstract}
Background: Stroke is one of the most common causes of death in industrialized countries and a leading cause of permanent disability in adults worldwide. Elettaria cardamomum is a nutraceuticalis that is used widely and characterized by numerous properties, such as remarkable effects on anxiety-like behavior features.

Objectives: This study aimed at determining the effect of Elettaria cardamomum essential oil and its major constituent (i.e., 1,8-cineole) on the brain injury caused by cerebral hypoperfusion among rats.

Methods: Cerebral hypoperfusion was induced in Wistar rats using the occlusion of the bilateral carotid artery for 30 min. Subsequently, Elettaria cardamomum essential oil $(25,50$, and $75 \mathrm{mg} / \mathrm{kg}$ i.p.) and its major constituent (1,8-cineole) $(5,10$, and $20 \mathrm{mg} / \mathrm{kg}$ i.p.) was injected to rats for 14 consecutive days. After the final treatment, blood samples were taken, and the brain tissues were separated and used for biochemical analysis by RT-PCR to detect the levels of proinflammatory cytokines.

Results: Administration of Elettaria cardamomum essential oil and 1,8-cineole significantly decreased the malondialdehyde and nitric oxide levels in the blood and brain cortex of the rat. Additionally, Elettaria cardamomum essential oil and 1,8-cineole significantly suppressed the expression level of Caspase 3, IL-1 $\beta$, TNF- $\alpha$, and iNOS in the cerebral cortex.

Conclusion: The findings suggest that Elettaria cardamomum essential oil includes remarkable neuroprotective impacts that may be beneficial to cerebral hypoperfusion treatment. The pharmacological property of Elettaria cardamomum partly requires the modulation of inflammatory mediators and oxidative stress.
\end{abstract}

Keywords: 1,8-cineole, Apoptosis, Cerebral hypoperfusion, Elettaria cardamomum

\section{Background}

The global rate of ischemic stroke is approximately 15 million cases each year. Few clinical benefits have been obtained from the clinical and preclinical studies conducted on the prevention of neuron damage during a stroke $(1,2)$. Production of reactive oxygen species (ROS) and high oxygen consumption leads to the low levels of endogenous antioxidant contents in nonreplicating neurons. Free radicals activate lipid peroxidation of polyunsaturated fatty acids that results in the membrane impairment of functional activity and its damage. Therefore, cerebral ischemic injury in the patient is the result of inflammation, oxidative stress, necrosis, and apoptosis (3-5).

The cardamom (Elettaria cardamomum [EC] L. [Maton] from Zingiberaceae family) is among the most widely cultivated crops in tropical regions mainly in India. Different parts of this plant have been traditionally used as a stomachic, retentive, digestive, antiemetic, and carminative herb in the treatment of gastrointestinal complications. Moreover, it can be utilized for its antiputrefactive effects during embalmment (6). In addition, pharmacological applications of the EC have been recently attributed to modern medicine due to its anti-inflammatory, antimicrobial, analgesic, anticonvulsant, and antidepression properties (7).

The EC essential oil analysis using gas chromatography-mass spectroscopy (GC-MS) technique has revealed 16 major compounds that constitute $93.62 \%$ of the total components of this plant. The detected compounds included oxygenated monoterpenes (63\%), $\alpha$-terpinyl acetate $(56.87 \%)$, monoterpenes (27.37\%), 1,8-cineole (23.74\%), $\alpha$ terpineol $(5.25 \%)$, limonene $(4.05 \%)$, sesquiterpenes $(1.43 \%)$, fatty acids esters $(1.17 \%)$, and acetates $(0.63 \%)(8)$.

Moreover, 1,8-cineole, which is also known as eucalyptol or cajeputol, is an oxidized terpene that has been found in eucalyptus (75\%), rosemary (40\%), psidium (40-60\%), and many other plant essential oils (9).

\section{Objectives}

Despite the reported pharmacological properties of the EC, there is a limited number of studies 
investigating its neuroprotective effects on the injury of cerebral ischemic-reperfusion. Therefore, the present study aimed at investigating the effect of EC essential oil and its major component (i.e., 1,8cineole) on the bilateral common carotid artery (BCCA) occlusion that induce the injury of cerebral ischemia-reperfusion in the Wistar rat model.

\section{Methods}

\subsection{Medicinal plant and the method for essential oil extraction}

Dried EC whole-plant was purchased from a local market in Izeh, Iran, and identified by a herbalist in Izeh Branch, Islamic Azad University, Izeh, Iran, by comparing it to a reference sample (specimen No., 78901). Initially, the plant was ground, and the essential oil was extracted in a Clevenger apparatus via water distillation. For this purpose, $50 \mathrm{~g}$ of the dried plant was weighed and transferred into a 500ml flask. Afterward, the plant was mixed with $200 \mathrm{ml}$ of distilled water and heated at $40^{\circ} \mathrm{C}$ to reach the distillation rate of $2-3 \mathrm{ml}$ per min. After four $\mathrm{h}$, the essential oil was collected and stored in a dark place at $-20^{\circ} \mathrm{C}(10)$.

\subsection{Detection of essential oil components by gas chromatography-mass spectroscopy}

An Agilent 5975 GC-MS system equipped with the HP-5MS fused silica column (30 m×0.25 mm I.D) was used to perform the GC-MS analysis. Oven and the injector temperature values were set at $50-240^{\circ} \mathrm{C}$ with a rate of $7^{\circ} \mathrm{C} / \mathrm{min}$ and $280^{\circ} \mathrm{C}$, respectively. Following that, helium gas flowed with a rate of 0.8 $\mathrm{mL} / \mathrm{min}$, and ionization energy was tuned to $70 \mathrm{eV}$ for scanning time of $1 \mathrm{sec}$ and mass range of 40-300 amu. Eventually, the compounds obtained from the essential oil were determined after making a comparison of the mass and library spectra, authentic compounds, and published literature (10).

\subsection{Experimental animal model}

Adult male Wistar rats (weight range: 250-300 g) were obtained from Pasteur Institute, Tehran, Iran. Subsequently, all animals were kept under a normal $12 \mathrm{~h}$ light-12 $\mathrm{h}$ dark cycle and laboratory conditions at $22 \pm 2{ }^{\circ} \mathrm{C}$ and $55 \%$ relative humidity. All study procedures were approved by the Institutional Animal Care and Committee of Sanandaj Branch, Islamic Azad University, Sanandaj, Iran.

\subsection{Animal grouping}

The rats were assigned randomly into eight groups $(n=7)$ of control (1), ischemia (Isc) (2), Isc+25EC (3), Isc+50EC (4), Isc+75EC (5), Isc+Cineole5 (6), Isc+Cineole 10 (7), and Isc+Cineole 20 (8). On the other hand, the control group received normal saline without the induction of cerebral Isc. The Isc rats in groups 3-5 were administered with 25,
50 , and $75 \mathrm{mg} / \mathrm{kg}$ of the EC essential oil for 14 days, respectively. Furthermore, the Isc rats in groups 6-8 were respectively administered with 5,10 , and 20 $\mathrm{mg} / \mathrm{kg}$ of 1,8-cineole for 14 days and afterward subjected to reperfusion for $24 \mathrm{~h}$. It is worth mentioning that the rats were sacrificed $24 \mathrm{~h}$ following reperfusion.

\subsection{Induction of ischemia}

The rats underwent bilateral common carotid artery occlusion under ketamine anesthesia (50 $\mathrm{mg} / \mathrm{kg}$ ) on day 14. Afterward, the animals were placed on their back, and atraumatic clamps for $30 \mathrm{~min}$ and $24 \mathrm{~h}$ reperfusion by removing the clamps were utilized to expose and occlude both carotid arteries. The temperature was maintained at $37 \pm 0.5^{\circ} \mathrm{C}$ during the surgical procedure.

\subsection{Measurement of biochemical parameters in animals}

The animals were sacrificed 14 days after the treatment that followed cerebral (Isc/reperfusion) by cervical decapitation. Subsequently, the blood samples were taken, and the brains were removed and washed with cooled $0.9 \%$ normal saline. They were then kept on ice and subsequently blotted on filter paper, weighed, and homogenized in cold phosphate buffer (0.05 M, pH=7.4).

\subsection{Detection of malondialdehyde levels}

Thiobarbituric acid (TBA) reactive substances in the serum, and brain tissue homogenates were determined using the incubation of $0.5 \mathrm{ml}$ of each serum or $10 \%$ of each homogenate with $15 \%$ trichloroacetic acid (TCA) plus $0.375 \%$ TBA and $5 \mathrm{~N}$ hydrochloric acids at $95^{\circ} \mathrm{C}$ for $15 \mathrm{~min}$.

The mixture was then cooled and centrifuged, followed by the measurement of supernatant absorbance at $512 \mathrm{~nm}$ against an appropriate blank.

\subsection{Antioxidant capacity detection}

The ferric reducing antioxidant power method was employed to measure the antioxidant capacity of the serum and brain homogenate tissue. This technique can reduce $\mathrm{Fe}^{3+}$ ions to $\mathrm{Fe}^{2+}$ in the presence of TPTZ2 reagent that leads to the TPTZ-Fe ${ }^{2+}$ blue complex accompanied by a maximum absorbance value of $593 \mathrm{~nm}$.

\subsection{Detection of nitric oxide levels}

In this procedure, $100 \mu \mathrm{l}$ of each serum or tissue homogenate (in triplicate) were added into the wells of a 96-well plate. Afterward, $100 \mu \mathrm{l}$ of sulfanilamide solution $1 \mathrm{~g}$ sulfanilamide in $100 \mathrm{ml}$ phosphoric acid $5 \%$ ) was added to each well. The plate was then incubated in a dark place at room temperature for 510 min. Subsequently, $50 \mu$ l of NEDD solution was added to each well and incubated at room temperature for $30 \mathrm{~min}$. Eventually, the light 


\begin{tabular}{|c|c|}
\hline Coding gene & Primer sequence \\
\hline casp3-F* & AAGCCGAAACTCTTCATCATTCA \\
\hline casp3-R** & GCCATATCATCGTCAGTTCCAC \\
\hline Tnf $\alpha-F$ & CTGAACTTCGGGGTGATCGG \\
\hline Tnf $\alpha-R$ & GGCTTGTCACTCGAATTTTGAGA \\
\hline Il-1/-F & GAAATGCCACCTTTTGACAGTG \\
\hline Il-1 $\beta-R$ & TGGATGCTCTCATCAGGACAG \\
\hline Bax F & GAGGATGATTGCTGATGTGGATA \\
\hline Bax-R & CAGTTGAAGTTGCCGTCTG \\
\hline Bcl2-F & GGAGCGTCAACAGGGAGATG \\
\hline Bcl2-R & ACAGCCAGGAGAAATCAAACAGA \\
\hline iNOS-F & TCAGCCAAGCCCTCACCTAC \\
\hline iNOS-R & СТCСAATCTCTGCCTATCCGTCT \\
\hline
\end{tabular}

absorbance of the wells was read by an ELISA reader at the wavelength of $540 \mathrm{~nm}$, and the nitric oxide (NO) content of the samples was identified by making a comparison with a standard nitrite curve.

\subsection{Detection of IL-1 $\beta, T N F-\alpha$, iNOS, Caspase 3, and $B c l-2$ coding gene expression}

Adequate volumes of guanidium thiocyanate solution were used to freeze the brain samples. They were then kept at $-80^{\circ} \mathrm{C}$ until the RNA extraction, and total cellular RNA was extracted by the phenol/ chloroform method. In addition, the concentration of the total tissue RNA was estimated based on the light absorbance at the wavelength of $260 \mathrm{~nm}$. Moreover, the quality of the extracted RNA was verified by the agarose gel electrophoresis method. The purified total RNA was entered the reverse transcription process included the incubation of RNA $(1 \mu \mathrm{g})$ with oligo (dT) primer $(1 \mu \mathrm{M})$ and 200 units of Moloney murine leukemia virus reverse transcriptase from a Clontech first-strand complementary DNA (cDNA) synthesis kit.

In the next stage, an aliquot $(5 \mu \mathrm{l}$ of a $1 / 10$ dilution) of each synthesized cDNA was utilized for the reverse transcription-polymerase chain reaction (RT-PCR) method. Table 1 tabulates the PCR primers.

The amplification of DNA was performed in the solution containing $1 \times \mathrm{Taq}$ polymerase buffer, 1.5 $\mathrm{mM} \mathrm{MgCI}, 50 \mu \mathrm{M}$ dNTPs, $0.25 \mu \mathrm{M}$ of each $5^{\prime}$ and 3 'specific primers, $1 \mu \mathrm{Ci}[\alpha-32 \mathrm{p}]$, and 2 units Taq DNA polymerase (Promega $\mathrm{C}$ ) in a final volume of $50 \mu \mathrm{l}$. The mixture was overlaid with mineral oil and amplified for 30 cycles. The steps included denaturation at $94^{\circ} \mathrm{C}$ for $1 \mathrm{~min}$, primers annealing at $60^{\circ} \mathrm{C}$ for $1 \mathrm{~min}$, and extension at $72^{\circ} \mathrm{C}$ for $1 \mathrm{~min}$. The reaction was then terminated by a final extension at $72^{\circ} \mathrm{C}$ for $7 \mathrm{~min}$, and the PCR products were stored at $4^{\circ} \mathrm{C}$. Following that, the products of PCR were sizeseparated by $10 \%$ acryl/bis-acrylamide gel electrophoresis, followed by ethidium bromide staining $(15 \mu \mathrm{g} / \mathrm{ml})$. Table 1 displays the excision of each band from the gel and the measurement of the incorporated $32 \mathrm{p}$ quantity in a scintillation counter.

\subsection{Statistical analysis}

The data were analyzed in the GraphPad Prism 5 statistical software and expressed by mean \pm SEM. Moreover, a one-way ANOVA and multiple comparison Turkeys' test were utilized to determine the significant differences between the treated and control groups. A p-value less than 0.05 was considered statistically significant.

\section{Results}

Figures $1 \mathrm{~A}$ and $1 \mathrm{~B}$ indicate a remarkable improvement in the MDA levels in serum and brain tissues (cortex) among the Isc-induced rats, compared to the control group $(\mathrm{P}<0.001)$. Nonetheless, Iscmediated lipid peroxidation in serum and brain tissues (cortex) decreased in rats treated with EC essential oil $(25,50$, and $75 \mathrm{mg} / \mathrm{kg})$, compared to the control group $(\mathrm{P}<0.001)$. Furthermore, the
A

\section{Serum MDA}

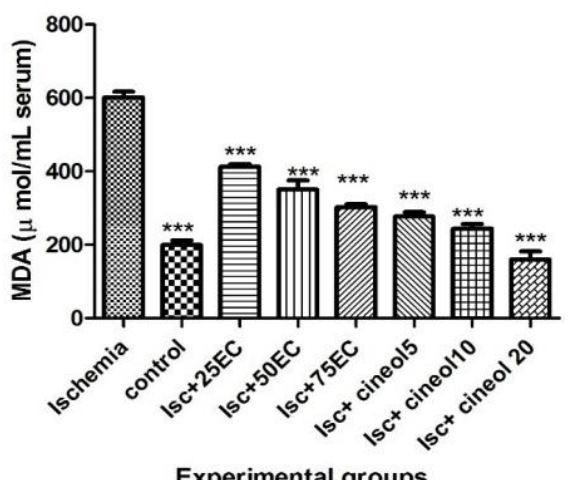

\section{B}

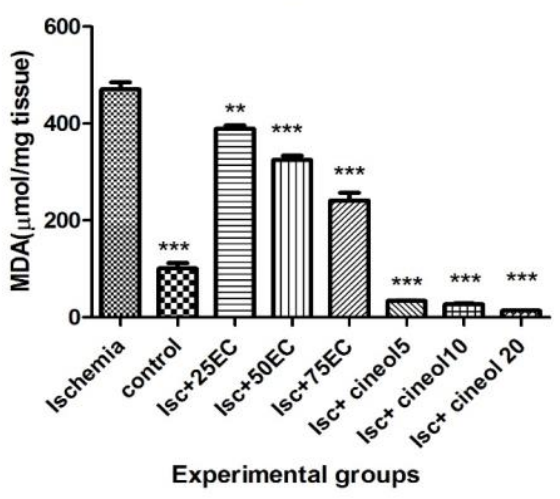

Figure 1. Effects of Elettaria cardamomum essential oil and 1,8-cineole on lipid peroxidation in serum (A) and brain tissues (B) following cerebral hypoperfusion, compared to the ischemia group. Values are presented as mean \pm SEM $(n=7)$.

Isc and EC show ischemia and Elettaria cardamomum, respectively.

${ }^{* * *}$ Represents the significant differences at $\mathrm{P}<0.001$. 
A

\section{Serum FRAP}

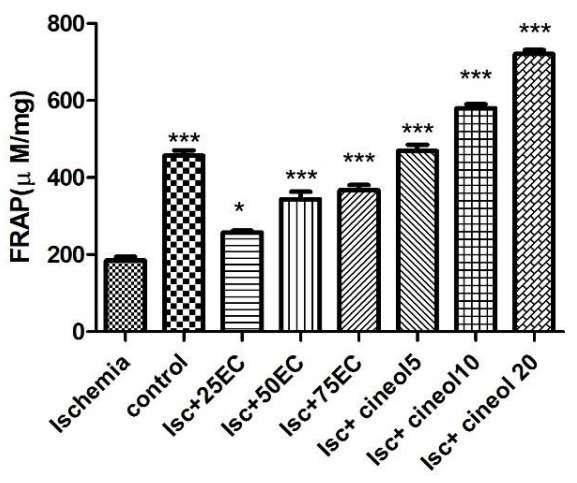

Experimental groups
B

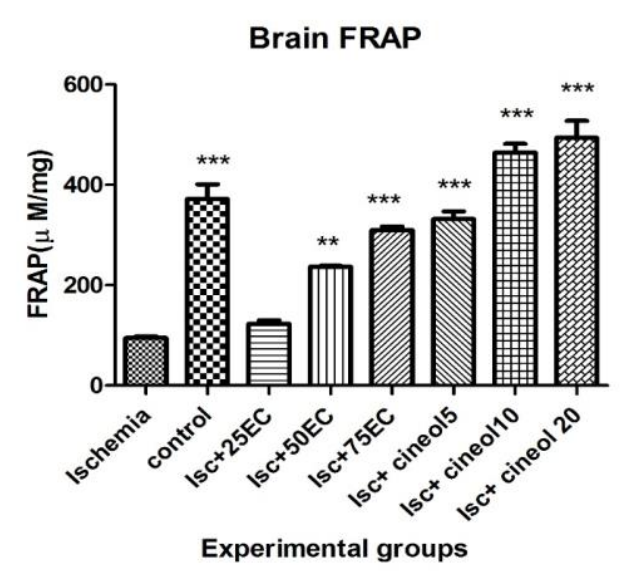

Figure 2. Effects of Elettaria cardamomum essential oil and 1,8-cineole on ferric reducing antioxidant capacity in serum (A) and brain tissues (B) following cerebral hypoperfusion, compared to the ischemia group. Values are presented as mean \pm SEM (n=7).

Isc and EC show ischemia and Elettaria cardamomum, respectively.

***, **, and * represent the significant differences at $\mathrm{P}<0.001, \mathrm{P}<0.01$, and $\mathrm{P}<0.05$, respectively.

administration of 1,8-cineole $(5,10$, and $20 \mathrm{mg} / \mathrm{kg})$ led to a decrease in the level of MDA in the serum and brain tissues (cortex) of the groups under treatment, compared to the Isc group $(\mathrm{P}<0.001)$.

As shown in Figures $2 \mathrm{~A}$ and $2 \mathrm{~B}$, the Isc group obtains a significant decrease in antioxidant capacity according to the ferric reduction in brain cortex and serum, compared to the control group $(\mathrm{P}<0.001)$. However, treatment with EC essential oil (50 and 75 $\mathrm{mg} / \mathrm{kg}$ ) enhanced the ferric reducing antioxidant capacity in the brain cortex, compared to the Isc group $(\mathrm{P}<0.001)$. Moreover, the administration of EC essential oil $(25,50$, and $75 \mathrm{mg} / \mathrm{kg})$ improved serum ferric reducing antioxidant capacity, compared to the Isc group $(\mathrm{P}<0.001)$. In addition, 1,8 -cineole $(5,10$, and $20 \mathrm{mg} / \mathrm{kg}$ ) led to the enhancement of the ferric reducing antioxidant capacity in the serum and brain tissue, compared to the Isc group $(\mathrm{P}<0.001)$.
As can be seen in Figures $3 \mathrm{~A}$ and $3 \mathrm{~B}$, BCCA occlusion for $30 \mathrm{~min}$ followed by $24 \mathrm{~h}$ reperfusion induces a significant increase in the NO level in serum and brain tissues, compared to the control group $(\mathrm{P}<0.001)$. Moreover, treatment with EC essential oil $(25,50$, and $75 \mathrm{mg} / \mathrm{kg})$ resulted in a significant decrease in the NO levels in serum and brain tissues. On the other hand, the rats that received 1,8-cineole (5, 10, and $20 \mathrm{mg} / \mathrm{kg})$ showed an Isc-induced increase in the NO levels in serum $(\mathrm{P}<0.001)$ (Figure $3 \mathrm{~A}$ ) and 1,8-cineole (5 and $10 \mathrm{mg} / \mathrm{kg}$ ) pretreatment leading to a decrease in the NO level in the brain tissue (Figure 3B).

The results from RT-PCR for the detection of Caspase 3, IL1- $\beta$, inducible nitric oxide synthase (iNOS), TNF- $\alpha$, and bcl 2 mRNAs in the brain of rats after $24 \mathrm{~h}$ reperfusion are illustrated in Figure 4 . An up-regulation was also observed in caspase-3

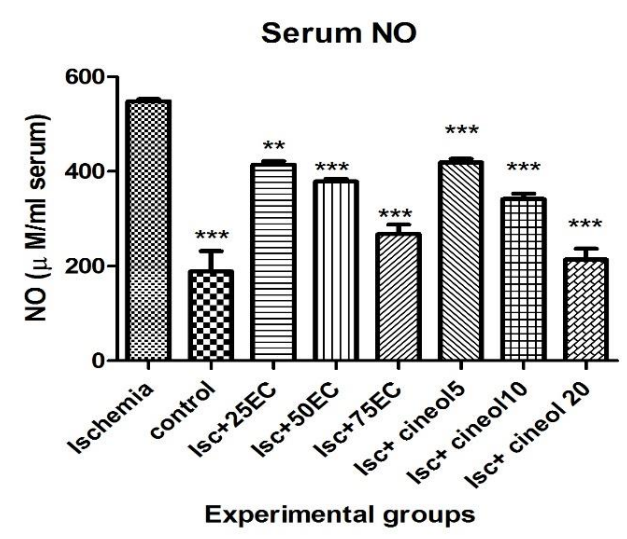

Brain NO

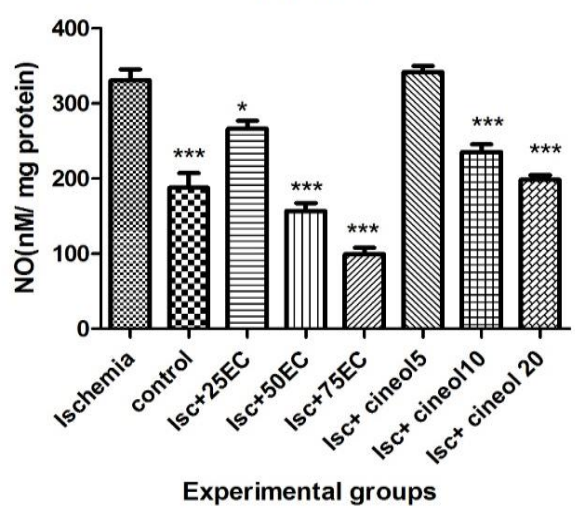

Figure 3. Effects of Elettaria cardamomum essential oil and 1,8-cineole on the NO levels in serum and brain tissues in the experimental groups, compared to the ischemia group. Data are represented as mean \pm SEM (n=7).

Isc and EC show ischemia and Elettaria cardamomum, respectively.

$* * *, * *$, and $*$ represent the significant differences at $\mathrm{P}<0.001, \mathrm{P}<0.01$, and $\mathrm{P}<0.05$, respectively. 
expression after cerebral hypoperfusion in the Isc group, compared to the control group $(\mathrm{P}<0.01)$ (Figure 4A). Furthermore, treatment with EC essential oil $(25,50$, and $75 \mathrm{mg} / \mathrm{kg})$ caused the suppression of the Caspase 3 expression levels in the cerebral cortex of the animals. In addition, Caspase 3 expression in the cerebral cortex was notably reduced by 1,8 -cineole treatment $(5,10$, and 20 $\mathrm{mg} / \mathrm{kg}$ ) (Figure 4A). Cerebral hypoperfusion also resulted in a significant and more sustained elevation of TNF- $\alpha$ mRNA in the cerebral cortex of the animals, compared to the control group $(\mathrm{P}<0.001)$ (Figure $3 \mathrm{~B})$.

Pretreatment with EC essential oil $(25,50$, and 75 $\mathrm{mg} / \mathrm{kg})$ and 1,8-cineole $(5,10$, and $20 \mathrm{mg} / \mathrm{kg})$ reduced TNF- $\alpha$ mRNA, compared to the Isc group (Figure 4B). Cerebral hypoperfusion also caused a significant increase in the expression of iNOS and IL$1 \beta$ in the cerebral cortex, compared to the control group (Figures 4C and 4D). Moreover, treatment with EC essential oil $(25,50$, and $75 \mathrm{mg} / \mathrm{kg})$ and 1,8cineole $(5,10$, and $20 \mathrm{mg} / \mathrm{kg})$ reduced the iNOS and IL-1 $\beta$ expression in the cerebral cortex of the Iscinduced rats, compared to the control group. Cerebral hypoperfusion also resulted in a decrease in $\mathrm{Bcl}_{2}$ expression of the cerebral cortex among the rats, compared to the control group $(\mathrm{P}<0.05)$ (Figure 4E).

A

B
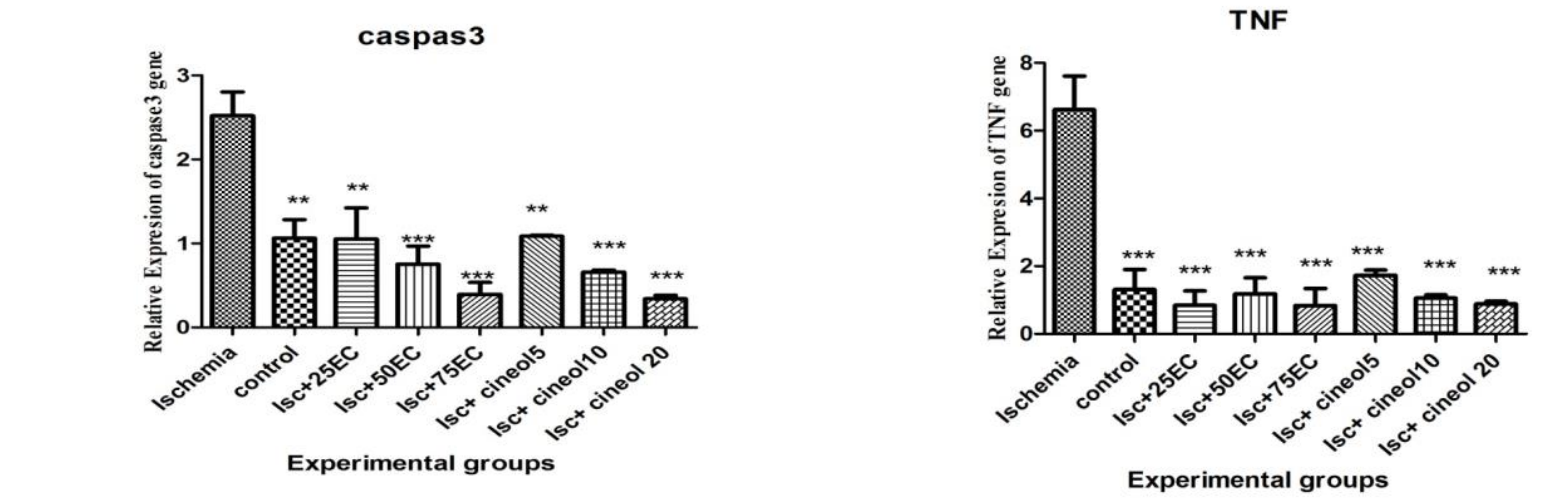

$\mathrm{C}$

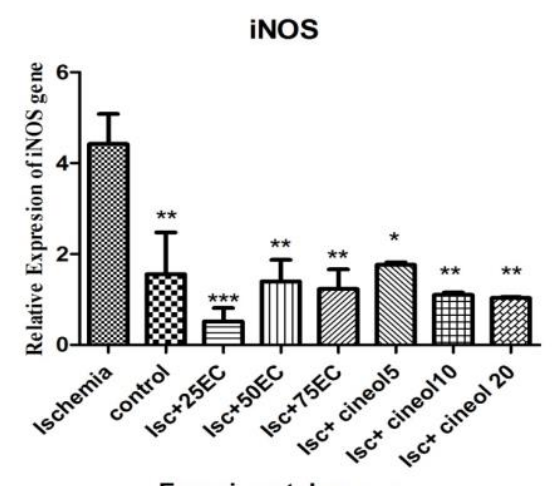

Experimental groups

D

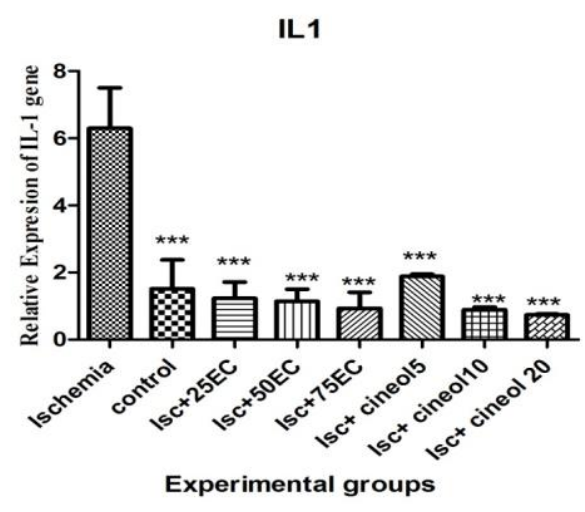

E

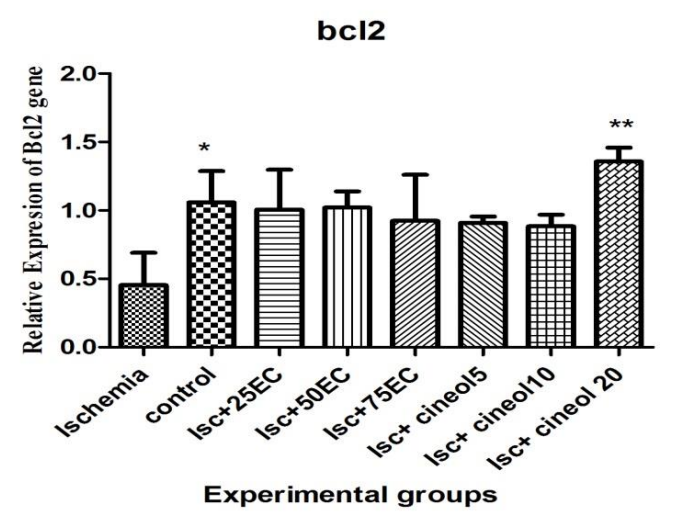

Figure 4. Effects of Elettaria cardamomum essential oil and 1,8-cineole on the expression of active caspase-3, IL1- $\beta$, iNOS, TNF- $\alpha$, and Bcl2 in the cerebral cortex of the rats homogenizing after $24 \mathrm{~h}$ reperfusion. Data are presented as mean \pm SEM.

Isc and EC show ischemia and Elettaria cardamomum, respectively.

$* * *, * *$, and ${ }^{*}$ represent the significant differences at $\mathrm{P}<0.001, \mathrm{P}<0.01$, and $\mathrm{P}<0.05$, respectively. 


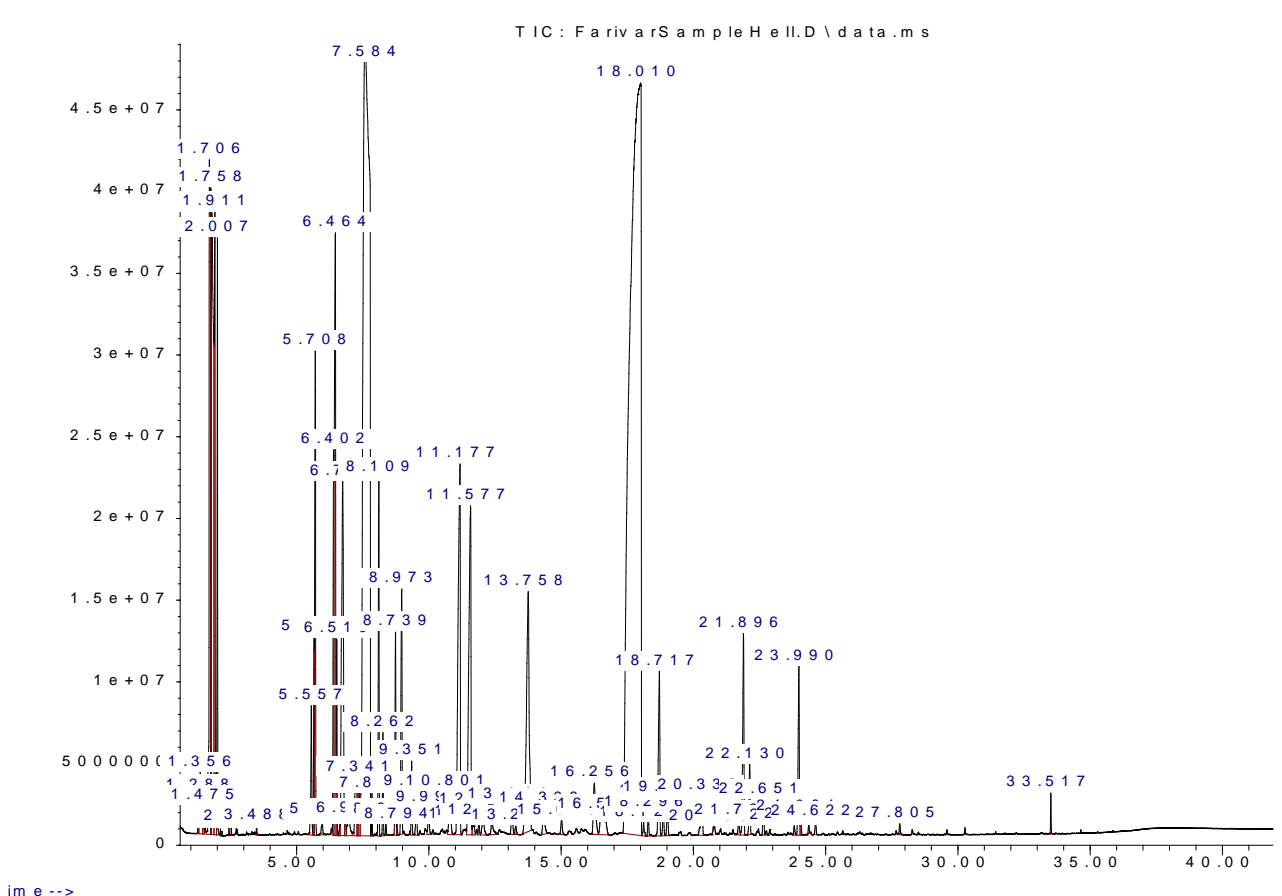

Figure 5. Phytochemical composition of Elettaria cardamomum essential oil

Pretreatment with 1,8-cineole $(20 \mathrm{mg} / \mathrm{kg})$ remarkably enhanced the expression of $\mathrm{Bcl}_{2}$ in the cerebral cortex among the animals, compared to the Isc group $(\mathrm{P}<0.001)$.

\subsection{Gas chromatography-mass spectroscopy analysis of Elettaria cardamomum essential oil}

According to the results of Figure 5, the major components of EC essential oil include 1,1-pmentheu-8-ylacetate 3-cy (34.65\%), 1,8 cineol 2oxabicyclo $(2,2 \ldots,(20.77 \%)$, and 1,3 cyclohexen-1-ol 4 methyl 1-1 (3.29\%).

\section{Discussion}

The results from biochemical parameter assessments showed that BCCA occlusion for $30 \mathrm{~min}$, followed by 24-h reperfusion, induced oxidative stress in the rat model. The findings in the present study are in line with the results of a previously conducted study on cerebral reperfusion injury (11). In this study, EC essential oil and 1,8-cineole showed an attenuation effect on the induction of MDA levels. This finding was consistent with earlier reports on the anti-inflammatory and antioxidant properties of the EC essential oil and 1,8-cineole. The antioxidant properties, elevation of glutathione levels, and reduction of LDL susceptibility to oxidation have been reported for cardamom (12).

Cerebral hypoperfusion produces excess free radicals and causes the suppression of the antioxidant defense system resulted in the induction of neuronal degeneration which can lead to death.
The EC essential oil contains compounds with antioxidant capacities, such as 1,8-cineole. Previous studies have documented the anti-oxidative properties of EC $(13,14)$ and 1,8-cineole $(15)$ in the experimental models that might indicate their effects on the prevention of cerebral Isc.

Nitric oxide (NO) is one of the major compounds that leads to cerebral reperfusion injury. The neutrophil-induced iNOS enhances the NO generation. Moreover, neuronal damage is a result of the excessive production of NO in oxidative stress. Moreover, the interaction of NO with superoxide anions mediates the NO-induced neuronal injury that resulted in the peroxynitrite anion generation. Peroxynitrite, as a highly reactive radical, can oxidize different cellular macromolecules (16). Therefore, the inhibition of these processes by EC essential oil and its major constituent (i.e., 1,8-cineole) accounts for the presently noticed attenuation of oxidative stress during reperfusion injury.

The 1,8-cineole can pass through the blood-brain barrier because of its fat-soluble content (17) leading to its protective effects on cortical cells against oxygen and glucose deprivation/reperfusion-evoked injury. This anti-ischemic potential is caused by the anti-oxidative properties of 1,8-cineole, as documented by the elevation of superoxide dismutase activity in the cells treated with 1,8-cineole and chemical scavenging of ROS (18).

The 1,8-cineole has shown experimental anti-inflammatory in-vitro and in-vivo effects by the inhibition of inflammatory mediator overexpression in lipopolysaccharide-treated human blood monocytes 
and amyloid $\beta$ cells treated with PC12 pheochromocytoma (19). Furthermore, 1,8-cineole has reduced the release of inflammatory cytokines IL-6 and IL-8 as well as NO, thereby alleviating the inflammatory phenotype of human umbilical vein endothelial cells (20).

The 1,8-cineole that has been detected among the major components of Achillea millefolium L. essential oil has been shown as a suppressor for the inflammatory responses of lipopolysaccharidestimulated RAW 264.7 macrophages according to its ability to decrease the level of NO and down-regulate iNOS, TNF- $\alpha$, and IL-6 (21). The TNF- $\alpha$ induces the local production of reactive nitrogen species through the induction of nitric oxide synthase leading to the elevation of oxidative stress responsible for brain injury. In addition, TNF- $\alpha$, as a pro-inflammatory cytokine, has different effects on the pathological processes, such as the induction of edema after Isc (22). The findings in this study showed that cerebral hypoperfusion enhanced the expression of TNF- $\alpha$ and IL-1 $\beta$ mRNA in the cerebral cortex. The downregulation of increased hippocampal TNF- $\alpha$ and IL-1 $\beta$ that was observed in the transient bilateral carotid artery occlusion rats treated with EC essential oil and 1,8-cineole may be responsible for the protective effects on cerebral hypoperfusion via the inhibition of the inflammatory response.

It should be noted that the obtained results are in line with those of the earlier studies on cerebral hypoperfusion injury (23). Apoptosis that occurs following cerebral hypoperfusion is one of the major pathways leading to cell death (24). The outer membranes of mitochondria become more permeable in response to the oxidation load resulting in the translocation of Bax from the cell cytoplasm to the mitochondria. This process leads to the release of cytochrome $c$ that normally existed in the mitochondrial inter-membrane space (25). This proapoptotic translocation of Bax protein is under the control of the Bcl-2 protein family. The entrance of cytochrome c into the cytoplasm results in the formation of the apoptosome that is a complex containing apoptotic-protease activating factor-1, procaspase-9, and ATP.

The apoptosome allows the auto-activation of procaspase-9, which is followed by the expression of procaspase- 3 , and the activated caspase- 3 catalyzes DNA fragmentation (26). According to the findings in the present study, the expression of caspase-3 was up-regulated after cerebral hypoperfusion injury. Moreover, the EC essential oil and 1,8-cineole pretreatment significantly suppressed the level of Caspase 3 expression in the cerebral cortex of the Wistar rats.

\section{Conclusion}

The results of the current study demonstrated the protective effects of EC essential oil and its major component (i.e., 1,8-cineole) against brain hypoperfusion in an animal model. Since chronic brain Isc and reperfusion induce the attenuation of oxidative stress and release of proinflammatory cytokines to the cerebral cortex, EC essential oil and 1,8-cineole can be proposed as potential natural therapeutics for the treatment of brain Isc and reperfusion.

\section{Acknowledgments}

The authors would like to thank the staff of the laboratory of Islamic Azad University of Sanandaj, Iran, for technical support. This study was extracted from a Ph.D. thesis (No: 110483732395782162253186).

\section{Footnotes}

Authors' Contribution: Mehrdad Farivar conceived and extracted the data; Zahra Hooshmandi designed the study, analyzed the data, and wrote the manuscript; Mahbubeh Setorki revised the paper and had full access to all of the data in the study; Sabrieh Amini who is the guarantor took the responsibility for the integrity of the data and the accuracy of the data analysis.

Conflict of Interests: The authors declare that there is no conflict of interest.

Ethical Approval: The study protocol was approved in 2019 by the Ethics Committee of Sanandaj Branch, Islamic Azad University, Sanandaj, Iran.

Informed consent: Written informed consent was obtained from legally authorized representatives before the study.

\section{References}

1. Mestriner RG, Miguel PM, Bagatini PB, Saur L, Boisserand LSB, Baptista PPA, et al. Behavior outcome after ischemic and hemorrhagic stroke, with similar brain damage, in rats. Behav Brain Res. 2013; 244:82-9. doi: 10.1016/j.bbr.2013.02.001. [PubMed: 23403282].

2. Matsumoto S, Murozono M, Kanazawa M, Nara T, Ozawa T Watanabe Y. Edaravone and cyclosporine A as neuroprotective agents for acute ischemic stroke. Acute Med Surg. 2018; 5(3):213-21. doi: 10.1002/ams2.343. [PubMed: 29988669].

3. Siesjö BK, Elmer E, Janelidze S, Keep M, Kristian T, Ouyang YB, et al. Role and mechanisms of secondary mitochondrial failure. Acta Neurochir Suppl. 1999;73:7-13. doi: 10.1007/978-37091-6391-7_2. [PubMed: 10494335].

4. Radak D, Resanovic I, Isenovic ER. Link between oxidative stress and acute brain ischemia. Angiology. 2014;65(8):66776. doi: 10.1177/0003319713506516. [PubMed: 24132856].

5. Margaill I, Plotkine M, Lerouet D. Antioxidant strategies in the treatment of stroke. Free Radic Biol and Med. 2005;39(4): 429-43. doi: 10.1016/j.freeradbiomed.2005.05.003. [PubMed: 16043015].

6. Jamal A, Javed K, Aslam M, Jafri MA. Gastroprotective effect of cardamom, Elettaria cardamomum Maton. fruits in rats. J Ethnopharmacol. 2006;103(2):149-53. doi: 10.1016/j.jep. 2005.07.016. [PubMed: 16298093].

7. Masoumi-Ardakani Y, Mandegary A, Esmaeilpour K, Najafipour $\mathrm{H}$, Sharififar F, Pakravanan M, et al. Chemical composition, 
anticonvulsant activity, and toxicity of essential oil and methanolic extract of Elettaria cardamomum. Planta Med. 2016;82(17):1482-6. doi: 10.1055/s-0042-106971. [PubMed: 27433883].

8. Mahmud S. Composition of essential oil of Elettaria cardamomum Maton leaves. Pakistan J Sci. 2008;60:111-4.

9. Santos F, Rao V. Antiinflammatory and antinociceptive effects of 1, 8-cineole a terpenoid oxide present in many plant essential oils. Phytother Res. 2000;14(4):240-4. doi: 10.1002/1099-1573(200006)14:4<240::aid-ptr573>3.0.co;2x. [PubMed: 10861965].

10. Ahmadvand H, Amiri H, Dalvand H, Bagheri S. Various antioxidant properties of essential oil and hydroalcoholic extract of Artemisapersica.J Birjand Univ Med Sci. 2014; 20(4):416-24.

11. Nakashima M, Niwa M, Iwai T, Uematsu T. Involvement of free radicals in cerebral vascular reperfusion injury evaluated in a transient focal cerebral ischemia model of rat. Free Radic Biol Med. 1999;26(5-6):722-9. doi: 10.1016/s0891-5849(98)002573. [PubMed: 10218662].

12. Sadeek EA, El-Razek FH. The chemo-protective effect of turmeric, chili, cloves and cardamom on correcting iron overload-induced liver injury, oxidative stress and serum lipid profile in rat models. J am Sci. 2010;6(10):7.

13. Singh G, Kiran S, Marimuthu P, Isidorov V, Vinogorova V. Antioxidant and antimicrobial activities of essential oil and various oleoresins of Elettaria cardamomum (seeds and pods). J Sci Food Agricul. 2008;88(2):280-9. doi: 10.1002/jsfa.3087.

14. Saeed A, Sultana B, Anwar F, Mushtaq M, Alkharfy KM, Gilani A$\mathrm{H}$. Antioxidant and antimutagenic potential of seeds and pods of green cardamom (Elettaria cardamomum). Int J Pharmacol. 2014; 10:461-9.

15. Ciftci O, Ozdemir I, Tanyildizi S, Yildiz S, Oguzturk H. Antioxidative effects of curcumin, $\beta$-myrcene and 1,8-cineole against 2,3,7, 8-tetrachlorodibenzo-p-dioxin-induced oxidative stress in rats liver. Toxicol Ind Health. 2011;27(5):447-53. doi: 10.1177/0748233710388452. [PubMed: 21245202].

16. Lerouet D, Beray-Berthat V, Palmier B, Plotkine M, Margaill I. Changes in oxidative stress, iNOS activity and neutrophil infiltration in severe transient focal cerebral ischemia in rats. Brain Res. 2002;958(1):166-75. doi: 10.1016/s00068993(02)03685-5. [PubMed: 12468042].

17. Satou T, Takahashi M, Kasuya H, Murakami S, Hayashi S, Sadamoto $K$, et al. Organ accumulation in mice after inhalation of single or mixed essential oil compounds. Phytother Res. 2013;27(2):306-11. doi: 10.1002/ptr.4723. [PubMed: 22581512].

18. Ryu S, Park H, Seol GH, Choi IY. 1,8-C ineole ameliorates oxygen-glucose deprivation/reoxygenation-induced ischaemic injury by reducing oxidative stress in rat cortical neuron/glia. J Pharm Pharmacol.2014;66(12):1818-26. doi: 10.1111/ jphp.12295.

19. Juergens UR, Stöber $M$, Vetter $H$. Inhibition of cytokine production and arachidonic acid metabolism by eucalyptol (1.8-cineole) in human blood monocytes in vitro. Eur J Med Res. 1998;3:508-10. [PubMed: 9810029].

20. Linghu $\mathrm{K}$, Lin $\mathrm{D}$, Yang $\mathrm{H}, \mathrm{Xu} \mathrm{Y}$, Zhang $\mathrm{Y}$, Tao $\mathrm{L}$, et al Ameliorating effects of 1, 8-cineole on LPS-induced human umbilical vein endothelial cell injury by suppressing NF- $\mathrm{KB}$ signaling in vitro. Eur J Pharmacol. 2016;789:195-201. doi: 10.1016/j.ejphar.2016.07.039. [PubMed: 27455900].

21. Chou ST, Peng HY, Hsu JC, Lin CC, Shih Y. Achillea millefolium L. essential oil inhibits LPS-induced oxidative stress and nitric oxide production in RAW 264.7 macrophages. Int J Mol Sci. 2013;14(7):12978-93. doi: 10.3390/ijms140712978. [PubMed: 23797659].

22. Chen AQ, Fang Z, Chen XL, Yang S, Zhou YF, Mao L, et al. Microglia-derived TNF- $\alpha$ mediates endothelial necroptosis aggravating blood brain-barrier disruption after ischemic stroke. Cell Death Dis. 2019;10(7):1-18. doi: 10.1038/s41419019-1716-9. [PubMed: 31221990].

23. Lee JH, Park SY, Shin YW, Hong KW, Kim CD, Sung SM, et al. Neuroprotection by cilostazol, a phosphodiesterase type 3 inhibitor, against apoptotic white matter changes in rat after chronic cerebral hypoperfusion. Brain Res. 2006;082(1):18291. doi: 10.1016/j.brainres.2006.01.088. [PubMed: 16516167].

24. Mattson MP, Duan W, Pedersen W, Culmsee C. Neurodegenerative disorders and ischemic brain diseases. Apoptosis. 2001;6(1-2):69-81. doi: 10.1023/a:1009676112184. [PubMed: 11321043].

25. Kowaltowski AJ, Castilho RF, Vercesi AE. Mitochondrial permeability transition and oxidative stress. FEBS lett. 2001;495(1-2):12-5. doi: 10.1016/S0014-5793(01)02316-X.

26. Li P, Nijhawan D, Budihardjo I, Srinivasula SM, Ahmad M, Alnemri ES, et al. Cytochrome $\mathrm{c}$ and dATP-dependent formation of Apaf-1/caspase-9 complex initiates an apoptotic protease cascade. Cell. 1997;91(4):479-89. doi: 10.1016/s0092-8674(00)80434-1. [PubMed: 9390557]. 